\title{
Preliminary Analysis of Ku-Band Rain Fade Data for Earth-to-Satellite Path Measured in Malaysia
}

\author{
Hassan Dao, Md. Rafiqul Islam, Khalid Al-Khateeb and Sheroz Khan \\ Department of Electrical and Computer Engineering \\ Faculty of Engineering, International Islamic University Malaysia \\ Jalan Gombak, 53100 Kuala Lumpur, Malaysia \\ rafiq@iium.edu.my
}

\begin{abstract}
The dynamic characteristics of rain fade slope are one of the important factors in the determination of the earth-to-space communication system availability. It is also useful in the design of the fade countermeasures. This paper investigates the rain fade slope which is one of the main features of fade dynamics with $0.1 \mathrm{~s}$, $0.5 \mathrm{~s}, 1 \mathrm{~s}, 2 \mathrm{~s}, 5 \mathrm{~s}$ and $10 \mathrm{~s}$ sampling time intervals. The rain fade slope model proposed by the ITU-R was compared with the corresponding statistics obtained from rain attenuation data measured using MEASAT3 downlink at Ku-band in Malaysia during May 2010 - June 2011. Significant discrepancies have been observed between the measured fade slope data and that predicted by the ITU-R prediction model with different sampling time interval.
\end{abstract}

Keywords; Rain fade slope, microwave link, rain attenuation.

\section{INTRODUCTION}

In satellite-earth communications are suffered from high attenuation due to rain. Malaysia is located in equatorial region that has rainfall rate at $0.01 \%$ of time is $126 \mathrm{~mm} / \mathrm{h}\left(R_{0.01}=126\right.$ $\mathrm{mm} / \mathrm{h}$ ) [1]. Since heavy rain fall rate may affect to link communication outage and low quality of service. Therefore, reliability maintenance is important to use suitable compensation techniques to counter excessive attenuation [2].

Development of adaptive fade counter-measure algorithms requires knowledge of the dynamic behavior of rain attenuation, to assess the required speed with which the system can track attenuation changes [3]. This paper investigates some dynamic behaviour of rain attenuation which is fade slope including fade slope parameters analysis. This paper presents an analysis of rain fade Slope satellite-earth communication link operating at $\mathrm{Ku}-$ Band in Kuala Lumpur, Malaysia. Moreover, available recommended prediction models for the dynamic factors are compared and discussed.

European Space Agency (ESA) method used 1s sampling time interval and differential step of $5 \mathrm{~s}$ to assess dynamic behaviour. This issue may lead to a false estimation of the slope due to error of longer step sampling time interval and may not allow the detection of the real dynamics of fade [4]. This paper is included and also highlighted the sampling time interval assessment.
The next section briefs on the research experimental setup. Section III describes data pre-processing before process secondorder statistical analysis. Section IV shows our results and analysis relevant to occurrence of different attenuation levels, fade slope standard deviation with sampling time interval and fade slope statistics with sampling time interval. Conclusion is expressed in section $\mathrm{V}$.

\section{EXPERIMENTAL SETUP}

Measurement system is carried out at rooftop of E-2 building, Kulliyyah of Engineering, International Islamic University Malaysia (IIUM) receiving signals from MEASAT 3 satellites downlink synchronously with rainfall intensity measurement by tipping bucket rain gauge from June 2010 May 2011 period have been utilized in this paper.

Table I. System parameters of the link

\begin{tabular}{|l|l|}
\hline Ground Station Location & $3.3^{\circ} \mathrm{N}, 101.7^{\circ} \mathrm{E}$ \\
\hline Beacon Frequency & $10.982 \mathrm{GHz}$ (Ku-Band ) \\
\hline Elevation Angle & $77.4^{\circ}$ \\
\hline Azimuth & $253^{\circ}$ \\
\hline Polarization & Vertical \\
\hline Antenna Diameter & $2.4 \mathrm{~m}$ \\
\hline Satellite Position & $91.5^{\circ} \mathrm{E}$ (MEASAT 3) \\
\hline
\end{tabular}

After receiving signal from MEASAT3 by parabolic dish antenna of 2.4 meter, the signal is down converted to L-band $(1.232 \mathrm{GHz})$ by Low noise block (LNB) having a noise figure of $0.3 \mathrm{~dB}$. The down converted signal is subsequently fed to spectrum analyzer through RG-11 coaxial cable, sampling rate $10 \mathrm{~Hz}$. Output of spectrum analyzer is sent to computer via General purpose interface bus (GPIB) cable and subsequently stored using sampling rate of $0.1 \mathrm{~s}$ using data logger developed by LabView. $0.2 \mathrm{~mm}$-Tipping bucket rain gauge is also measured and logged synchronously with every 10 s time interval in order to retrieve better data resolution. Parameters of the link and experimental diagram are summarized and shown in table I and Fig. 1, respectively. 


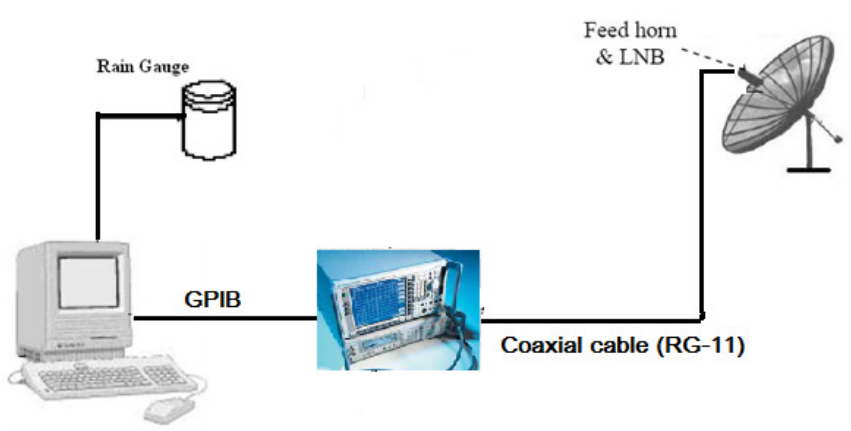

Figure 1. Experimental Setup at IIUM to measure receive signal level from MEASAT which is synchronized with real-time rain gauge.

\section{DATA PRE-PROCESSING}

In order to define the attenuation reference level $(A)$, instantaneous attenuation of the link can be determined from the received signal level. However, attenuation level due to rain is determined during the rain event expressing in Fig. 2.

During raining events, received signal contains two main components occurring concurrently such as rain attenuation and scintillation phenomena. The phenomena demonstrate an additive effect on the satellite signal level variation, filtering with appropriate cutoff frequency is an effective technique to separate out the two propagation effects [5].Therefore, fast fluctuation due to scintillation cause is necessarily to filter before analysis [6].

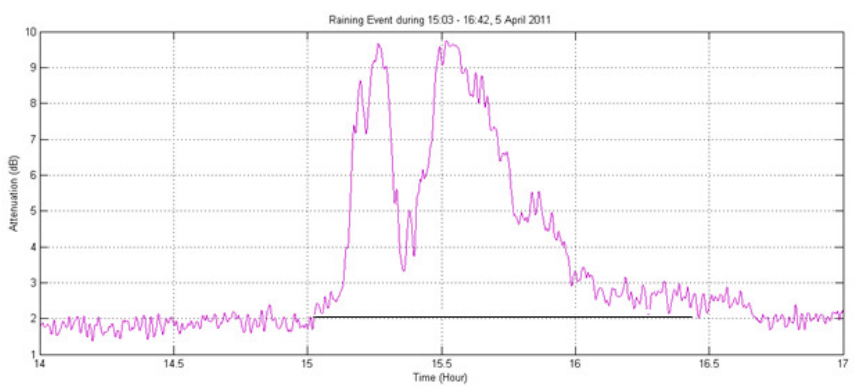

Figure 2. Raining event recorded on $5^{\text {th }}$ April 2011 during 15:02 - 16:43.

Karasawa and Matsudo [5] proposed periodogram method of power spectrum density (PSD) technique to separate out two propagation effects occurring by chosen suitably cutoff frequency and subsequently low-pass filter (LPF) being used to remove scintillation effect from the rain attenuation. Fig.3 depicts a periodogram PSD during raining event during 15:02 16:43, on $5^{\text {th }}$ April 2011 exhibiting from the slope line, suitable cutoff frequency is $25 \mathrm{mHz}$.

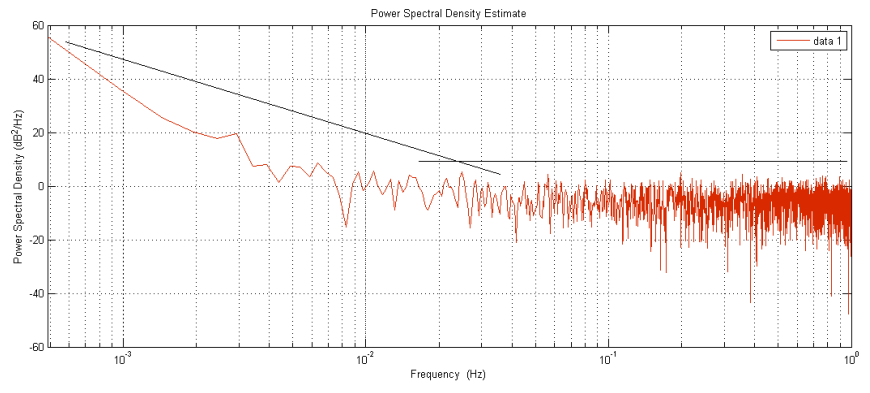

Figure 3. Power spectral density (PSD) of the attenuation time series.

Moreover, attenuation time series were filtered with $0.5 \mathrm{~s}$, $1 \mathrm{~s}, 2 \mathrm{~s}, 5 \mathrm{~s}$ and $10 \mathrm{~s}$ integration of time by using Sampling time method and averaging method for analyzing interval time effect of fade slope.

Once scintillation has been removed, fade slopes are calculated for each attenuation threshold in terms of fixed attenuation levels. The fade slope is defined as the rate of change of rain attenuation $A(t)$ calculated [7],[9] by equation (1),

$$
\delta(t)=\frac{A(t+\Delta t)-A(t)}{\Delta t} \quad(d B / s)
$$

Where $\Delta \mathrm{t}$ is sampling interval time (s), $t$ is sample number and $A$ is attenuation level (dB) where is calculated [10] if,

$$
A-0.5<A(t) \leq A+0.5 d B \text {. }
$$

\section{RESULTS AND ANALYSIS}

\section{A. Occurrence of Different Attenuation Levels}

Number of time series (second) used for the signal in the fade slope analysis is shown in Fig. 4. Lower attenuation depths have a greater number of times while higher attenuations have less than number of time. This tendency is able to be attributed to the fact that different attenuations are caused by different atmospheric conditions.

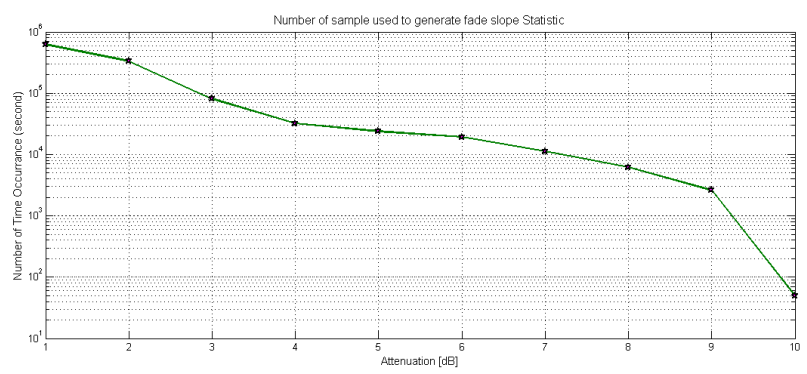

Figure 4. Number of time series (second) used to generate fade slope for attenuation level from $1 \mathrm{~dB}$ to $10 \mathrm{~dB}$. 


\section{B. Fade Slope Standard Deviation with Sampling Time Interval}

Standard deviations of fade slope as a function of attenuation varying by interval times are presented in Fig.6. The standard deviations by averaging method (solid line) is lower when compare to sampling method (dash line). $0.5 \mathrm{~s}$, $1 \mathrm{~s}$ and $2 \mathrm{~s}$ standard deviations have been close among them when compare to $5 \mathrm{~s}$ and $10 \mathrm{~s}$ time interval. The standard deviations increase gradually up to $6 \mathrm{~dB}$ and decrease from $7 \mathrm{~dB}$ to $10 \mathrm{~dB}$.

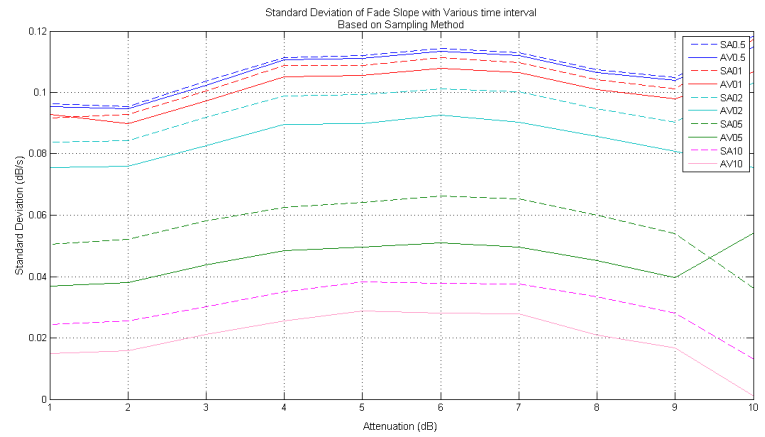

Figure 6. Standard deviation as a function of attenuation level comparing with various interval times

Parameter $s$ is important and also interested in fade slope model. ITU-R [8] refer $s$ parameter is depended on climate and elevation angle and over average value in Europe and USA is 0.01 . In order to determine s parameter for the link, equation (2) is applied.

Based on above equation (2), $s$ parameter is equal to 0.0406 and 0.0414 for averaging method and sampling method, respectively. Thus s parameter equals to 0.041 earned from the mean of the values.

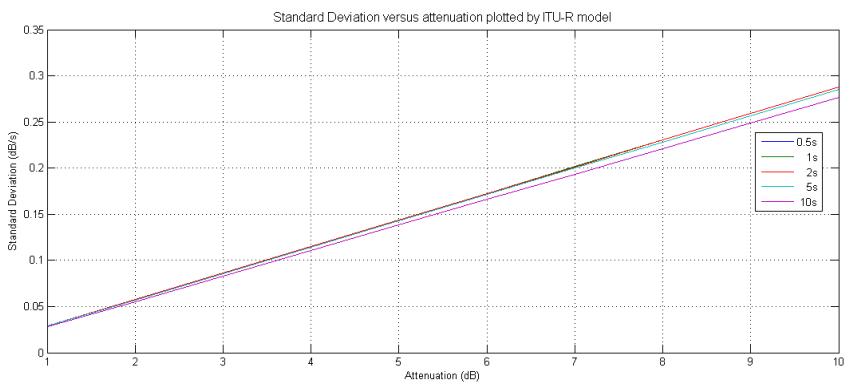

Figure 7. Standard deviation model proposed by ITU-R

$$
s=\frac{\sigma_{\xi}}{F_{\theta} \cdot(t) A}
$$

Where: $F\left(f_{B}, \Delta t\right)$ is function of cutoff frequency and interval time determined from equation (3)

$$
F\left(f_{b}, \Delta t\right)=\sqrt{\frac{2 \pi^{2}}{\left(1 / t_{a}+(2 \Delta)^{b}\right)^{1 / b}}}
$$

Where $f_{B}$ is $3 \mathrm{~dB}$ cutoff frequency and $b$ is equal to 2.3 .

ITU-R model has proposed the model based on measurement from temperate region which is linear function increasing with attenuation calculated from equation (2) by substitution of $F(f, \Delta t)$ and attenuation $A$, the result is shown in Fig. 7. In addition, interval time is slightly affected to the standard deviation while measured standard deviation is obviously shown that the measurement result be totally different from the model. Thus, it is important the model should be modified or revised in order to match with other region.

\section{Fade Slope Statistics with Sampling Time Interval}

Statistics relationship of fade slope and attenuation is presented in probability density function (PDF) and cumulative distribution function (CDF) being generated by storing fade slope values in bins of size $0.001 \mathrm{~dB} / \mathrm{s}$ to support enormous number of time series. The values were rounded to the closest bin value rather than being fixed at a certain number of decimal places.

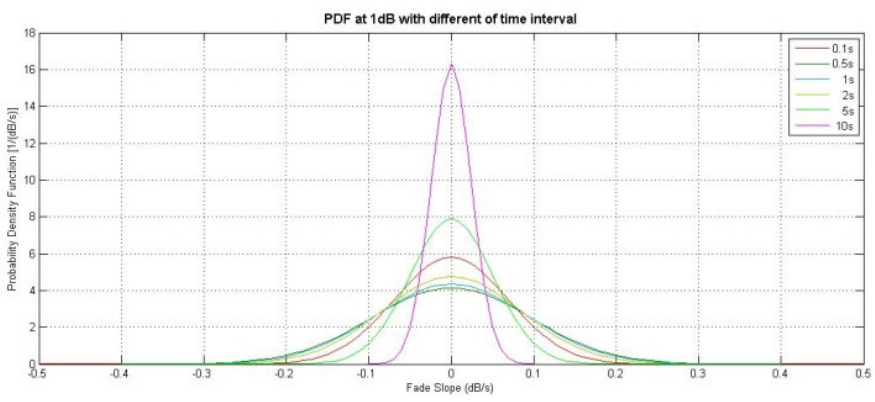

Figure 8. PDF of fade slope at $1 \mathrm{~dB}$ attenuation varying with time intervals from $0.1,0.5,1,2,5$ and $10 \mathrm{~s}$

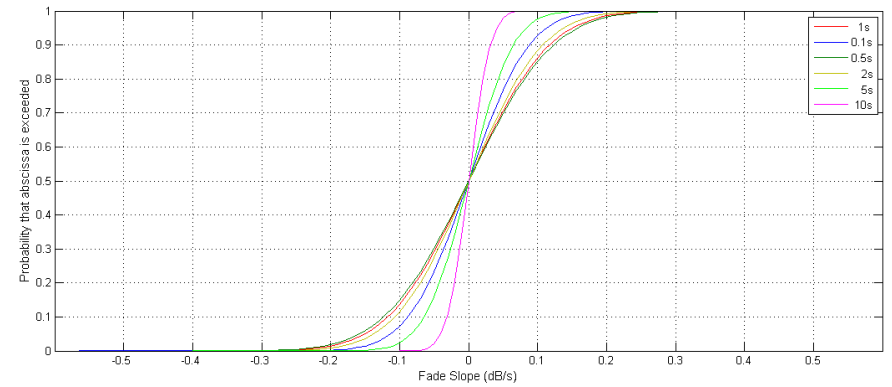

Figure 9. Cumulative distribution function of fade slope of $0.1 \mathrm{~s}, 0.5 \mathrm{~s}, 1 \mathrm{~s}$, $2 \mathrm{~s}, 5 \mathrm{~s}$ and $10 \mathrm{~s}$ 
Another interesting aspect of fade slope is effect of interval time to fade slope. Fig. 8 shows examples of PDF of fade slope for different time intervals and Fig.9 depicts CDF of fade slope for different time intervals. Both figures show indicate that fade slope is more close to zero $\mathrm{dB}$ when sampling of time increases.

Times Intervals $0.1 \mathrm{~s}, 0.5 \mathrm{~s}$ and $1 \mathrm{~s}$ are appropriate the need of rapid control loop fulfillment that may be implemented in uplink power control (ULPC) techniques whereas $2 \mathrm{~s}, 5 \mathrm{~s}$ and $10 \mathrm{~s}$ time intervals are more suitable for slower control loop.

\section{CONCLUSION}

Rain fade on earth-space communication links from MEASAT has been measured for 12 months at IIUM campus in Kuala Lumpur. Data has been analyzed for investigating the effect of sampling time on fade slope characteristics. The rain fade occurrence indicates that the lower rain attenuation occurs more frequently than higher attenuation.

The standard deviation of measured rain fade slopes were investigated at $0.1 \mathrm{~s}, 0.5 \mathrm{~s}, 1 \mathrm{~s}, 2 \mathrm{~s}, 5 \mathrm{~s}$ and $10 \mathrm{~s}$ sampling intervals and compared with that predicted by ITU-R. Significant discrepancies were observed between the measured and predicted standard deviation and consequently fade slope distribution. Hence these parameters need to be revised and modify in order to predict fade slope distribution accurately in tropical region.

\section{ACKNOWLEDGEMENT}

The authors are very grateful to Research Management Centre (RMC) of International Islamic University Malaysia (IIUM) for supporting this research through Endowment Type B grant.

\section{REFERENCES}

[1] J.S. Mandeep, "Equatorial Rainfall Measurement on Ku-Band Satellite Communication Downlink", Progress in Electromagnetics Research, PIER 76, 2007.

[2] C. Ayama and T. Nguyen, "Fade and interfade durations on earth-space links in temperate and tropical locations", International Union of Radio Science-URSI Proceeding GA06, 2005

[3] L. Castanet and M.V. de Kamp, "Modelling the Dynamic properties of the propagation channel", 5th Management Committee Meeting of the COST 280 Action, May 2003.

[4] F.F. Franklin, K. Fujisaki, and M. Tateiba, "Fade Dynamics on EarthSpace Paths at Ku-Band in Fukuoka, Japan Fade-Slope Evaluation, Comparison, and Model", IEEE Antenna and Wireless Propagation Letters, Vol. 5, 2006.

[5] Karasawa and Matsudo, "Characteristics of fading on low elevation earthspace paths where rain attenuation and scintillation occur concurrently", IEEE Trans. Antennas Propagation,Vol. 39, May 1991
[6] MR Islam, H. Dao and AH Zayuod, "Rain Fade Slope Analysis for Terrestrial Microwave Link in Malaysia", $9^{\text {th }}$ Malaysia International Conference on Communications (MICC) Proceeding, December 2009.

[7] L. Castanet and M.V. de Kamp, "Modelling the Dynamic properties of the propagation channel", 5th Management Committee Meeting of the COST 280 Action, May 2003

[8] "Prediction method of Fade dynamics on Earth-Space paths", Recommendation of the ITU-R, Rec. P.1623, 2003.

[9] MR Islam, J. Chebil, O. Khalifa, S. Khan, H. Dao and AH. Zyoud "Effect of Frequency on Fade Slope Based on Rain Attenuation Data Measured in Malaysia", International Conference on Computer and Communication Engineering (ICCCE 2010) proceeding, May 2010

[10] AH. Zyoud, H. Dao, MR Islam, J. Chebil, K. Al-Khateeb TA. Rahman "Fade Dynamics Analysis for Terrestrial Microwave Links", International Conference on Computer and Communication Engineering (ICCCE 2010) proceeding, May 2010. 